\title{
An active learning curriculum improves fellows' knowledge and faculty teaching skills: a medical student perspective
}

This article was published in the following Dove Press journal:

Advances in Medical Education and Practice

8 August 2017

Number of times this article has been viewed

\section{Mubariz Ahmad \\ Nourah AlHennawi \\ Maaham Ahmed}

Manchester Medical School, The University of Manchester, Manchester, UK
Correspondence: Mubariz Ahmad Manchester Medical School, The University of Manchester, Stopford Building, Oxford Road, Manchester, MI3 9PT, UK

Tel +44 I6I 2755540

Email mubariz.ahmad@student. manchester.ac.uk

\section{Dear editor}

We read with great interest the article by Inra et $\mathrm{al}^{1}$ which discusses the benefits of using an active learning curriculum to improve faculty teaching skills and help fellows retain more knowledge compared to traditional teaching methods. As current medical students, we can vouch for the effectiveness of this approach in improving the way material can be taught, hence would like to offer our perspective on this.

The study conducted on gastroenterology fellows evaluated the use of an active learning method to improve knowledge base and boost gastroenterology training exam (GTE) results. The results suggested an improvement in GTE scores and an increase in learner satisfaction compared to lecture-based teaching. A similar study was carried out in undergraduate medical education in the neurological field which looked at the effectiveness of team-based learning with real patients. This assessed the effects on knowledge retention and in-class engagement. The outcome matched that of the currently analyzed study, emphasizing the need for adapting newer methods of delivering teaching. ${ }^{2}$

At Manchester Medical School, problem-based learning (PBL) is the mainstay of teaching, which is conducted in small groups with an average of eight students led by a trained facilitator. Every session carries a predetermined learning agenda which is achieved through research, followed by discussions by all attendees. Despite having a number of lectures, we found PBL to be more advantageous to our learning due to its proactive nature which we found to be engaging. This positively impacted our ability to retain and apply medical knowledge. In addition to this, it improved our conceptual understanding and we believed it enhanced our overall exam performance. Preeti et al emphasized PBL's active approach in harvesting interest and motivation among students. ${ }^{3}$

While the implementation of this active gastroenterology learning curriculum has proven to be of significant benefit, there are several areas that can be potentially modified to improve outcomes. Reducing session timings helps maintain attention span and levels of engagement. Additionally, decreasing attendee numbers creates more opportunity for participation and allows the facilitator to dedicate more attention to each attendee. Although the multiple choice questions and immediate feedback assessment technique tickets are beneficial for self-assessment, it is more practical to use a unified polling system where fellows vote for the answers. This anonymizes results but enables the 
monitoring of individual performances for progression to be assessed. Finally, recording these sessions and providing the material on an online portal facilitates fellows' revision, when the material needs to be revisited.

In conclusion, the efficacy of lectures in conveying information has been questioned, as more active methods of teaching have provided better practical learning. Motivation is an essential component in maintaining stamina in the medical field, anything to improve this, such as active learning will go a long way in improving the experience of acquiring medical knowledge.

\section{Disclosure}

The authors report no conflicts of interest in this communication.

\section{References}

1. Inra JA, Pelletier S, Kumar NL, Barnes EL, Shields HM. An active learning curriculum improves fellows' knowledge and faculty teaching skills. Adv Med Educ Pract. 2017; 8:359-364.

2. Alimoglu MK, Yardim S, Uysal H. The effectiveness of TBL with real patients in neurology education in terms of knowledge retention, in-class engagement, and learner reactions. Adv Physiol Educ. 2017; 41(1):38-43.

3. Preeti B, Ashish A, Shriram G. Problem based learning (PBL) - an effective approach to improve learning outcomes in medical teaching. $J$ Clin Diagn Res. 2013; 7(12):2896-2897. 


\section{Authors' reply}

Jennifer A Inra',2

Stephen Pelletier ${ }^{2}$

Navin L Kumar ${ }^{1,2}$

Edward L Barnes 3,4

Helen M Shields ${ }^{1,2}$

'Division of Gastroenterology, Hepatology and Endoscopy, Brigham and Women's Hospital, ' ${ }^{2}$ arvard Medical School, Boston, MA, ${ }^{3}$ Division of Gastroenterology and Hepatology, University of North Carolina, Chapel Hill, NC, ${ }^{4}$ University of North Carolina

School of Medicine, Chapel Hill, NC, USA

Correspondence: Jennifer A Inra

Department of Medicine, Harvard

Medical School, Brigham and Women's

Hospital, 75 Francis Street, ASB2, Boston,

MA 02115 , USA

Tel +l 6177326389

$\mathrm{Fax}+\mathrm{I} 6179780840$

Email jinra@partners.org

\section{Dear editor}

We appreciate the thoughtful comments received from Ahmed et al regarding our article "An active learning curriculum improves fellows' knowledge and faculty teaching". ${ }^{1}$

The educational literature supports the recommendation that the optimal timing for a lecture is $10-15$ minutes, as a student's attention may wander or wane after that time. ${ }^{2}$ This ideal time limit stems from a paperby Hartley in 1978, which recommends this optimal time frame. ${ }^{3}$ The majority of these recently published manuscripts supporting this time frame, however, do not provide primary data on attention or attention span; they base their recommendations on the manuscript by Hartley. We do agree, however, that shorter sessions may help maintain attention span based on anecdotal personal experiences, and therefore constructed our sessions with 15 minutes devoted to multiple choice questions and a question and answer period, and only 30-45 minutes of active content presentation by two different presenters.

In addition, we agree that small groups are often more successful in encouraging learners to participate. However, it is not feasible to present this material more than once to smaller groups, given the busy schedules of presenters and of fellows. Our sessions typically had 10-15 fellows per session. We held our interactive learning sessions in a conference room around a table, fostering a comfortable learning environment, rather than sitting in rows as in a traditional lecture hall.

Online polling systems are easy to use and practical. We decided to use scratch tickets as fellows may get paged out of conference or arrive late, and we believed that it was easier to begin participating if an IF-AT ticket (Epstein Educational Enterprises, Cincinnati, OH, USA) is in front of them, rather than having to log into a mobile device.

In the future, we hope to record these sessions for online viewing. Our current conference room does not have appropriate capabilities to videotape sessions. We are actively looking into holding our sessions in another convenient location for our busy fellows that also gives us adequate recording ability.

\section{Disclosure}

The authors have no conflicts of interest in this communication.

\section{References}

1. Inra JA, Pelletier S, Kumar NL, Barnes EL, Shields HM. An active learning curriculum improves fellows' knowledge and faculty teaching skills. Adv Med Educ Pract. 2017; 8:359-364.

2. Bradbury NA. Attention span during lectures: 8 seconds, 10 minutes, or more? Adv Physiol Educ. 2016;40(4):509-513.

3. Hartley J, Davies IK. Note taking: a critical review. Program Learn Educ Tech. 1978;15: 207-224.

Dove Medical Press encourages responsible, free and frank academic debate. The content of the Advances in Medical Education and Practice 'letters to the editor' section does not necessarily represent the views of Dove Medical Press, its officers, agents, employees, related entities or the Advances in Medical Education and Practice editors. While all reasonable steps have been taken to confirm the content of each letter, Dove Medical Press accepts no liability in respect of the content of any letter, nor is it responsible for the content and accuracy of any letter to the editor.

\section{Publish your work in this journal}

Advances in Medical Education and Practice is an international, peerreviewed, open access journal that aims to present and publish research on Medical Education covering medical, dental, nursing and allied health care professional education. The journal covers undergraduate education, postgraduate training and continuing medical education including emerging trends and innovative models linking education, research, and health care services. The manuscript management system is completely online and includes a very quick and fair peer-review system. Visit http://www.dovepress.com/testimonials.php to read real quotes from published authors. 